\title{
The effect of atorvastatin on inflammatory markers in sulfur mustard gas induced bronchitis: a randomized double-blinded, placebo-control clinical trial
}

\author{
Behrooz Momeni ${ }^{1}$, Saeed Nazer², Seyed Masoom Masoompour ${ }^{3^{*}}$ (D), Bita Geramizadeh ${ }^{4}$ and \\ Seyed Vahid Sajadi ${ }^{5}$
}

\begin{abstract}
Background: This study was performed to evaluate the anti-inflammatory effect of atorvastatin in patients with chronic bronchitis, exposed to sulfur mustard gas.

Methods: In this randomized double-blinded clinical trial we recruited patients with chronic bronchitis after exposure to sulfur mustard gas. Ninety men 45-75 years old diagnosed with chronic bronchitis after exposure to mustard gas during the Iran-Iraq war, were randomly assigned to receive either atorvastatin (40 $\mathrm{mg}$ ) or placebo once a day for 3 months. The interleukin 6 (IL-6), tumor necrosis factor a (TNF-a), procalcitonin, highly sensitive CRP and COPD assessment test (CAT) score was compared at baseline and after 12 weeks.
\end{abstract}

Results: After consuming atorvastatin for 12 weeks, IL-6 level (mean difference $[95 \% \mathrm{Cl}] ; 0.2[-0.05,0.5]$ ), TNF- $a$ (mean difference $[95 \% \mathrm{Cl}] ;-0.07[-0.2,0.07]$ ), high sensitive CRP (mean difference $[95 \% \mathrm{Cl}]-0.1[-1.2,0.9]$ ), and procalcitonin (mean difference [95\% Cl]; $0.003[-0.02,0.03]$ ) did not change significantly. However, in the placebo group, only IL-6 (mean difference [95\%CI]; $0.6[0.2,1.05]$ ) decreased significantly after 12 weeks, but levels of high sensitive CRP (mean difference $[95 \% \mathrm{Cl}] ;-0.3[-1.4,0.8]$ ) TNF-a (mean difference $[95 \% \mathrm{Cl}] ;-0.2[-0.34,-0.06]$ ) and procalcitonin (mean difference $[95 \% \mathrm{Cl}] ; 0.02[-0.001,0.04])$ did not change significantly. After 12 weeks, the mean differences in TNF- a, IL-6 level, high sensitive CRP, procalcitonin, and CAT score did not significantly differ between the two groups.

Conclusions: The administration of $40 \mathrm{mg}$ atorvastatin for 3 months did not significantly change the inflammatory markers or the quality of life of patients exposed to mustard gas with chronic bronchitis.

Trial registration: IRCT, IRCT138904144312N1. Registered 16 August 2014, https://en.irct.ir/trial/4577.

Keywords: Chronic bronchitis, Statins, Atorvastatin, Sulfur mustard gas

*Correspondence: masoomm@sums.ac.ir

${ }^{3}$ Non-Communicable Diseases Research Center, Department of Internal

Medicine, School of Medicine, Shiraz University of Medical Sciences,

Shiraz, Iran

Full list of author information is available at the end of the article

\section{Background}

Sulfur mustard (2-bis-chloroethyl-sulfide) was discovered in 1821, and for the first time it was used during the First World War [1]. Due to its chemical alkylating compound, it can be easily absorbed through skin, respiratory system, ocular system, and genital tract [2]. Its toxicity is attributed to the lipophilic nature, which allows it to quickly penetrate target tissues and alkylate proteins, 
lipids and nucleic acids, resulting in DNA damage and cytotoxicity [3].

Unfortunately, sulfur mustard gas was used by the Iraqi army during the Iran-Iraq war 1980-1988. And a result, over 100,000 soldiers who did not have gas masks, suffered severe injuries, of which approximately 45,000 still continue to suffer the consequences of their exposure to this toxin [1]. Since the Iran-Iraq war, many Iranian war veterans have been admitted to hospitals with clinical manifestations of chemical gas poisoning, especially sulfur mustard gas [4]. These patients mostly suffer from respiratory problems, as the greatest causes of long-term disability, which include chronic bronchitis $(58.9 \%)$ and asthma (10.6\%) [5-7].

Both experimental and human trials have exhibited the involvement of inflammatory cells and mediators in sulfur mustard gas induced lung injuries. For instance, animal studies on rodents and pigs showed that exposure to sulfur mustard gas increases inflammatory cells in the upper and lower respiratory track for weeks or even months [8-13]. Furthermore, neutrophils and eosinophils numbers increased in the human lungs for long periods after exposure to sulfur mustard gas [14, 15]. However, the specific role of the inflammatory cells in sulfur mustard gas induced toxicity is not clear yet. In other models of lung injury, macrophages release inflammatory mediators with a key role in the pathogenesis of toxicity [16]; hence, it seems that they might play a similar role in the pulmonary response to sulfur mustard gas.

Hydroxymethyl-glutaryl (HMG) coenzyme A (CoA) reductase inhibitors (statins) have several modulatory effects, especially on neutrophils, which includes modulation of the innate and adaptive immune systems as well as the reduction of neutrophil migration [17-19]. This is in line with previous findings, stating that statins suppress major histocompatibility complex class II (MHCII)-mediated $\mathrm{T}$ cell activation, in order to modulate host inflammatory cell recruitment by downregulating the activation of early inflammatory response gene nuclear factor B [20].

Therefore, we hypothesized that statins might be able to improve symptoms in patients with chronic bronchitis by reducing airway inflammation. Hence, the aim was to evaluate the anti-inflammatory effect of atorvastatin amongst patients with chronic bronchitis due to sulfur mustard gas inhalation. And the reason why we chose atorvastatin, was its low side effect and also because its anti-inflammatory effects are more than simvastatin [21].

\section{Methods}

\section{Trial design}

The present study is a two parallel randomized doubleblinded, placebo-control trial group. We recruited only patients with chronic bronchitis due to sulfur mustard gas inhalation who referred to the pulmonary clinics affiliated with Foundation of Martyrs and Veterans Affairs, Shiraz, Iran. This study protocol was submitted and approved by institutional research board (IRB) of Ethics Committee of Shiraz University of Medical Sciences. After explaining the study objectives, all the participants gave their written informed consent. The trial was registered with the Iranian Clinical Trials Registry (IRCT138904144312N1; www.irct.ir).

\section{Participants}

Ninety men between the age of 45-75 years old diagnosed with chronic bronchitis due to mustard gas inhalation during the eight years Iran-Iraq war were consecutively recruited from the outpatient clinic (chronic bronchitis characterized by a cough productive of sputum daily for over three months duration during two consecutive years and airflow obstruction). Exclusion criteria included a history of exacerbation of symptoms within the past 4 weeks, connective tissue disease, sarcoidosis, eosinophilic granuloma, pneumoconiosis, lymphoma, carcinomatous, active tuberculosis, chronic liver disease, and currently taking statins or those who used it within the last 3 months prior to the study. In addition, those who smoked or were former smokers, who had stopped smoking less than 1 year were also excluded from the study.

\section{Interventions and outcomes}

The patients were randomly assigned to receive either atorvastatin $(40 \mathrm{mg}$ ) or placebo (starch pills, made by Shiraz Pharmacology School, Iran), given orally once a day for 3 months. The shape and packing of both pills was similar, so patients and the researches were blinded to the treatment group allocation.

Demographic data; including age, body mass index (BMI), heart rate, respiratory rate, systolic and diastolic blood pressure, and drug history of each patient was recorded in a date sheet. In addition, blood tests including total cholesterol, triglyceride (TG), liverfunction tests (LFTs), hemoglobin ( $\mathrm{Hb})$, and spirometry were recorded at the baseline. The primary outcome of this study was to assess systemic inflammation status at 3 months compared with baseline, measured by white blood cell (WBC) count, interleukin 6 level (IL-6), and tumor necrosis factor $\alpha$ (TNF- $\alpha)$. Also, we considered COPD assessment test (CAT) as the secondary outcomes. CAT is a patient-completed instrument to assess and quantify health-related quality of life and symptom burden in patients with COPD. It comprises of 8 questions, and each present a semantic 6-point (0-5) differential scale, providing a total score out of 40 . The higher 
scores exhibit the severity of COPD impact on a patient's life. [22].

\section{Measurements}

All assessments were performed at baseline and the end of intervention. The IL- 6 and TNF- $\alpha$, concentrations were measured with enzyme linked immunosorbent assay (ELISA) commercial kits (Platinum, Austria) according to the manufacturer's instructions. The reference range of IL- 6 and TNF- $\alpha$ serum level were considered $1.8 \mathrm{pg} / \mathrm{ml}$ and up to $2.8 \mathrm{pg} / \mathrm{ml}$. The high sensitive CRP concentration was measured with enzyme linked immunosorbent assay (ELISA) commercial kits (Diagnostics Biochem Canada Inc., Canada) according to the instructions of manufacturer. The serum level of high sensitive CRP less than $10 \mathrm{mg} / \mathrm{l}$ was considered as normal. The procalcitonin (PCT) level was measured via an automatic analyzer, the VIDAS ${ }^{\circledR}$ B.R.A.H.M.S PCT assay (bioMérieux, Marcy L'Etoile, France). The reference range of PCT was less than $150 \mathrm{pg} / \mathrm{ml}$. BMI was calculated, using the weight and height measurements. Blood pressure was measured after a 5 -min resting period with the individual sitting in a chair and determined, using a standard mercury sphygmomanometer. Moreover, the total CAT score was calculated for each patient by summing the points for each variable.

\section{Randomization}

Randomization sequence was created, using random block sizes of 4 and 6 . On the order of referral, the participants were allocated 1:1 into two groups. Study pills were allocated in separate packs blinded and labeled, using a four-digit code. The information regarding which codes correspond to what treatment was maintained secret by the project coordinator. The patients, attending physicians, staff involved in the pulmonary clinics, and members collecting and analyzing data were all blinded to the intervention allocation.

\section{Statistical analysis}

All statistical analyses were performed with the Statistical Package for Social Sciences version 19.0 (SPSS Inc., Chicago, IL, USA). We estimated that a total of 90 participants required to detect significant difference between the groups, with a two-tailed $\alpha$ of 0.05 and a $(1-\beta)$ of 0.80 , for a comparison of 2 independent mean of outcome with effect size of 0.6. The Kolmogorov-Smirnov test was used to test normality of variables' distribution. The baseline characteristics of both groups were compared, using X2 tests or Fisher's exact test for proportions. For continuous variables, independent groups were compared, using the t-test or Mann-Whitney test, whereas paired comparison was made, using paired t-test or Wilcoxon test.
Data are reported as means \pm SD. A two-sided $P$ value less than 0.05 was considered to be statistically significant. The effect size and $95 \%$ confidence interval of effect size of variables were calculated, using online calculators $[23,24]$.

\section{Results}

Out of the 90 patients assessed for eligibility, one individual declined further participation. Thus, the final number of patients being randomized into two groups was 89 (45 in atorvastatin and 44 in the placebo groups). Three participants in the placebo group and two in the atorvastatin group left the study due to personal reasons and three patients from each group were lost to follow-up. Finally, 40 patients were enrolled in atorvastatin group and 38 were enrolled in the placebo group (Fig. 1). Three patients in each group were on long term oxygen therapy.

The mean age of the patients was $50.3 \pm 5.7$ (range 45-71) years and the mean BMI of the patients was $26.1 \pm 5.1 \mathrm{~kg} / \mathrm{m}^{2}$. The baseline characteristics of the patients are reported in four main categories including; demographics \& clinical, baseline spirometry, blood tests, systemic inflammation markers, quality of life and medications (Table 1). Except for lower serum ALT (U/ $\mathrm{ml}$ ) in the atorvastatin group (mean difference [95\% CI] $-8.1[-14.7,-1.5])$, there was no significant difference between the two study groups with respect to baseline characteristics. The mean CAT score was $29.4 \pm 7$, ranging from 13 to 40 in atorvastatin group and $28.1 \pm 6$, ranging from 14 to 40 in the placebo group (mean difference $[95 \% \mathrm{CI}]: 0.57[-2.5,3.7])$.

There was no statistically significant difference between the treatment interval with respect to white blood cells (WBCs) in the atorvastatin group (mean difference [95\% $\mathrm{CI}]: 0.01[-0.6,0.63])$, and likewise in the placebo group (mean difference [95\% CI]: $-0.01[-0.45,0.41]$ ). In other words, in comparison with the placebo group, WBC did not significantly change in the atorvastatin group at the end of the study (mean difference $[95 \% \mathrm{CI}]:-0.03[-0.8$, 0.7]). Thereafter, the effects of atorvastatin and placebo on the serum levels of TNF- $\alpha$, IL-6, high sensitive CRP, and procalcitonin were investigated after 12 weeks of treatments. After 12 weeks of using atorvastatin $(n=40)$, the level IL-6 (mean difference [95\%CI]; $0.2[-0.05,0.5]$ ), TNF- $\alpha$ (mean difference $[95 \% \mathrm{CI}] ;-0.07[-0.2,0.07]$ ), high sensitive CRP (mean difference $[95 \% \mathrm{CI}]-0.1[-1.2$, $0.9]$ ), and procalcitonin (mean difference [95\% CI]; 0.003 $[-0.02,0.03])$ did not change significantly. In the placebo group $(\mathrm{n}=38$ ), only IL-6 (mean difference [95\%CI]; 0.6 $[0.2,1.05])$ significantly decreased after 12 weeks, but the levels of high sensitive CRP (mean difference [95\%CI]; $-0.3[-1.4,0.8]$ ) TNF- $\alpha$ (mean difference $[95 \% \mathrm{CI}] ;-0.2$ $[-0.34,-0.06]$ ) and procalcitonin (mean difference 


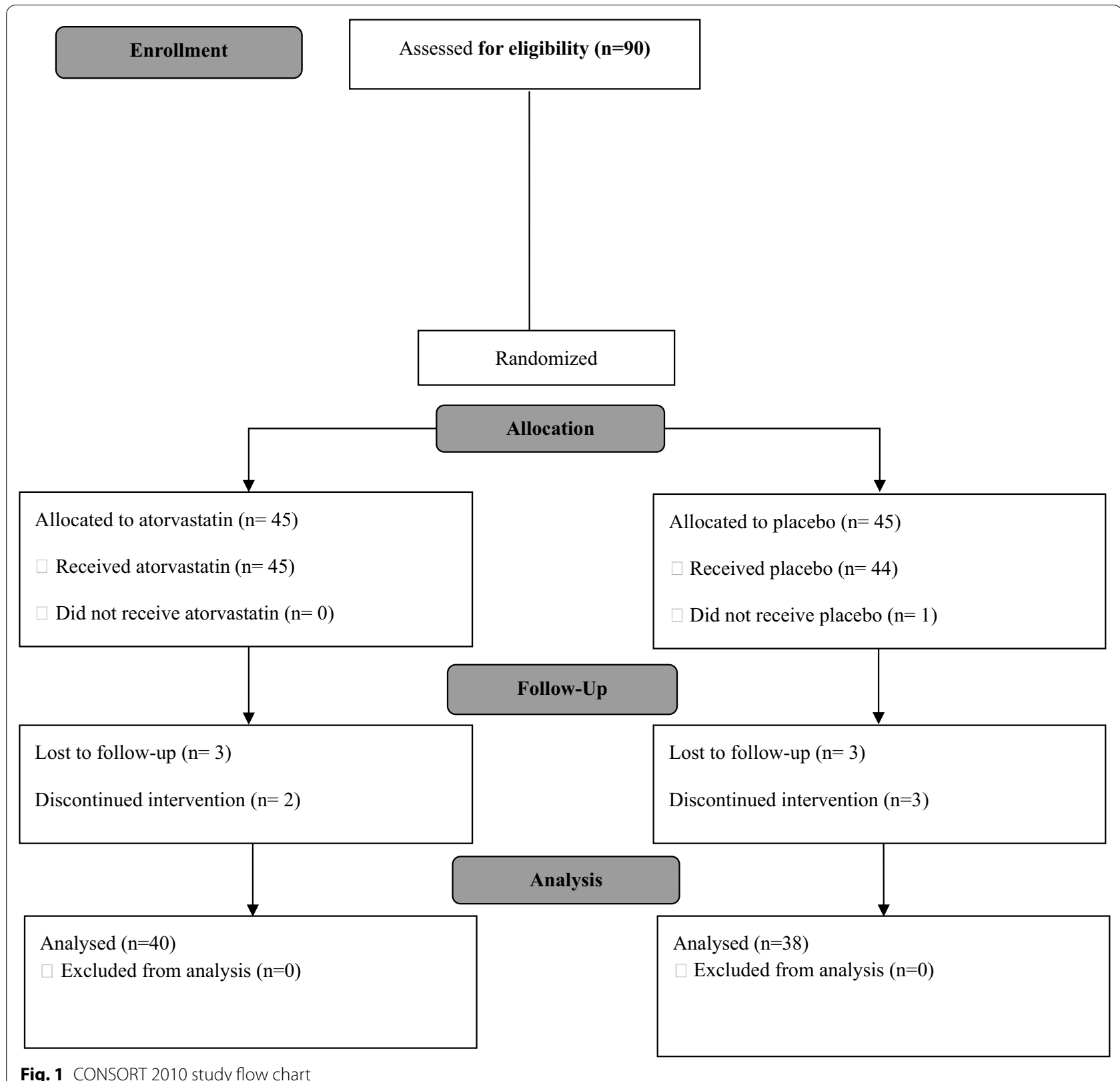

Fig. 1 CONSORT 2010 study flow chart

[95\%CI]; $0.02[-0.001,0.04])$ did not change significantly. The mean differences in levels of TNF- $\alpha$, IL-6, high sensitive CRP, and procalcitonin did not differ statistically between the study groups after 12 weeks. Table 2 shows changes in inflammatory markers after 12 weeks in the atorvastatin and placebo groups and between groups.

We compared changes of CAT score after the study interventions in each group. Although after 12 weeks in the atorvastatin and placebo groups the CAT score have met the minimum clinically important difference of a 2-unit reduction (mean difference [95\% CI]: 7.8 [5.3,
$10.3]$ and mean difference $[95 \% \mathrm{CI}]: 8.4[6.4,10.4]$ respectively), its mean difference did not change significantly between the two groups (mean difference [95\% CI]: 0.57 $[-2.5,3.7])$ (Table 2).

\section{Discussion}

This is the first study to evaluate the effect of atorvastatin on systemic inflammatory markers and quality of life in mustard gas induced bronchitis with a randomized, control and double-blinded designed. 
Table 1 The baseline characteristics of the study patients

\begin{tabular}{|c|c|c|c|c|c|}
\hline & $\begin{array}{l}\text { Atorvastatin Group } \\
(n=40)\end{array}$ & $\begin{array}{l}\text { Placebo Group } \\
(n=38)\end{array}$ & Mean difference $(95 \% \mathrm{Cl})$ & Effect size $(95 \% \mathrm{Cl})$ & $p$ value \\
\hline \multicolumn{6}{|l|}{ 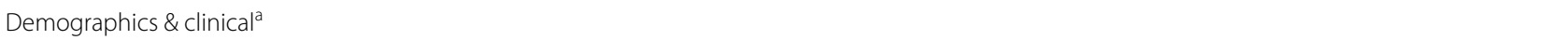 } \\
\hline Age (years) & $51 \pm 5.5$ & $49.7 \pm 5.9$ & $1.4(-1,3.8)$ & $-0.25(-0.7,0.19)$ & $0.10^{c}$ \\
\hline $\mathrm{BMI}\left(\mathrm{kg} / \mathrm{m}^{2}\right)$ & $27 \pm 5.5$ & $25 \pm 4.3$ & $1.8(-.03,3.9)$ & $-0.4(-0.85,0.04)$ & 0.08 \\
\hline Heart rate (beats/min) & $78.6 \pm 9$ & $78.9 \pm 10$ & $-0.3(-4.2,3.7)$ & $0.03(-0.41,0.47)$ & $0.84^{c}$ \\
\hline $\begin{array}{l}\text { Respiratory rate (inhalation-exhalation } \\
\text { cycles/min) }\end{array}$ & $15.7 \pm 2.3$ & $15.1 \pm 2.3$ & $0.6(-0.4,1.6)$ & $-0.26(-0.7,0.18)$ & $0.23^{c}$ \\
\hline Systolic blood pressure $(\mathrm{mmHg})$ & $115.6 \pm 14$ & $119.2 \pm 14$ & $-3.6(-9.5,2.4)$ & $0.25(-0.18,0.7)$ & $0.26^{c}$ \\
\hline Diastolic blood pressure $(\mathrm{mmHg})$ & $72.9 \pm 9$ & $76.1 \pm 8$ & $-3.2(-6.8,0.3)$ & $0.37(-0.07,0.82)$ & $0.07^{c}$ \\
\hline Mean FEV1/FVC & $66.4 \pm 9$ & $66.7 \pm 10$ & $0.007(-0.035,0.049)$ & $0.03(-0.41,0.47)$ & 0.90 \\
\hline \multicolumn{6}{|l|}{ COPD classification } \\
\hline FEV1 $\geq 80 \%, n(\%)$ & $22(55 \%)$ & $20(54.1 \%)$ & & & 0.97 \\
\hline $50 \leq \mathrm{FEV} 1<80, \mathrm{n}(\%)$ & $11(27.5 \%)$ & $11(29.7 \%)$ & & & \\
\hline $30 \leq \mathrm{FEV} 1<50, \mathrm{n}(\%)$ & $7(17.5 \%)$ & $6(16.2 \%)$ & & & \\
\hline \multicolumn{6}{|l|}{ Blood tests $^{\mathrm{a}}$} \\
\hline Hemoglobin (g/dl) & $15.4 \pm 1.9$ & $15.7 \pm 1.6$ & $-0.3(-1,0.5)$ & $0.17(-0.27,0.61)$ & 0.46 \\
\hline Serum AST (U/ml) & $21.8 \pm 7$ & $24.1 \pm 12$ & $-2.3(-6.4,1.8)$ & $0.23(-0.21,0.68)$ & $0.49^{c}$ \\
\hline Serum ALT (U/ml) & $20.6 \pm 10$ & $28.7 \pm 19$ & $-8.1(-14.7,-1.5)$ & $0.53(0.08,0.98)$ & $0.007^{c}$ \\
\hline Serum alkaline phosphatase (U/I) & $206 \pm 47$ & $193 \pm 49$ & $12(-8,32)$ & $-0.27(-0.71,0.17)$ & 0.23 \\
\hline Total Cholesterol (mg/dl) & $206 \pm 42$ & $211 \pm 85$ & $-4.7(-32,23)$ & $0.07(-0.36,0.51)$ & 0.74 \\
\hline Low-density lipoprotein (mg/dl) & $124 \pm 33$ & $119 \pm 30$ & $4.8(-8.6,18.3)$ & $-0.15(-0.6,0.28)$ & 0.47 \\
\hline $\mathrm{TG}(\mathrm{mg} / \mathrm{dl})$ & $174 \pm 89$ & $149 \pm 114$ & $25(-18,67)$ & $-0.24(-0.69,0.2)$ & 0.25 \\
\hline \multicolumn{6}{|l|}{ Systemic inflammation markers ${ }^{\mathrm{a}}$} \\
\hline White blood cells $\left(\times 10^{3}\right.$ cells per $\left.\mathrm{ml}\right)$ & $7.6 \pm 2.5$ & $6.7 \pm 1.7$ & $0.9(-0.09,1.8)$ & $-0.41(-0.86,0.03)$ & 0.052 \\
\hline IL-6 (pg/ml) & $0.92 \pm 0.87$ & $1.1 \pm 1.3$ & $-0.16(-0.67,0.35)$ & $0.16(-0.28,0.6)$ & $0.81^{c}$ \\
\hline TNF-a (pg/ml) & $2.1 \pm 0.4$ & $1.9 \pm 0.3$ & $0.16(-0.01,0.34)$ & $-0.4(-0.85,0.04)$ & $0.10^{c}$ \\
\hline $\mathrm{HsCRP}(\mathrm{ng} / \mathrm{ml})$ & $5.35 \pm 3.2$ & $4.10 \pm 2.9$ & $1.2(-1.2,2.6)$ & $-0.4(-0.85,0.04)$ & 0.07 \\
\hline Procalcitonin (pg/ml) & $0.043 \pm 0.18$ & $0.038 \pm 0.07$ & $0.005(-0.06,0.07)$ & $-0.03(-.048,0.4)$ & $0.20^{c}$ \\
\hline \multicolumn{6}{|l|}{ Quality of life ${ }^{a}$} \\
\hline CAT score & $29.4 \pm 7$ & $28.1 \pm 6$ & $1.24(-1.46,3.95)$ & $-0.19(-0.64,0.24)$ & 0.36 \\
\hline \multicolumn{6}{|l|}{ Medication ${ }^{\mathrm{b}}$} \\
\hline Inhaled corticosteroids & $4(10 \%)$ & $5(14.7 \%)$ & & & 0.81 \\
\hline Inhaled anticholinergics & $6(15 \%)$ & $4(11.1 \%)$ & & & 0.77 \\
\hline Inhaled $\beta 2$ agonists & $19(47.5 \%)$ & $15(41.7 \%)$ & & & 0.72 \\
\hline Antihypertensive & $13(31.7 \%)$ & $13(38.2 \%)$ & & & 0.67 \\
\hline Antidiabetics & $5(12.5 \%)$ & $4(11.8 \%)$ & & & 0.87 \\
\hline Mucolytic & $15(37.5 \%)$ & $14(41.2 \%)$ & & & 0.79 \\
\hline
\end{tabular}

a Average, standard deviation

b Frequency and percentages

c Mann-Whitney test

The primary goal of this study was to evaluate the hypothesis that can atorvastatin reduce inflammatory markers in patients with mustard gas induced chronic bronchitis? However, this study could not find any significant reduction in the atorvastatin group inflammatory markers (IL6, TNF- $\alpha$, HsCRP, and procalcitonin) at the level of $5 \%$. Nevertheless, TNF- $\alpha$ serum levels increased significantly in the placebo group. Although the exact explanation is unclear, the IL6 reduction in this group may be explained by regression to mean theory [25].

In one hand, several studies could show the antiinflammatory effect of statin [26, 27]; however, few could not $[28,29]$. Considering the significant reduction in serum cholesterol level in the atorvastatin group, it is unlikely that poor adherence to the study protocol was the reason for the failure to reach statistical differences 


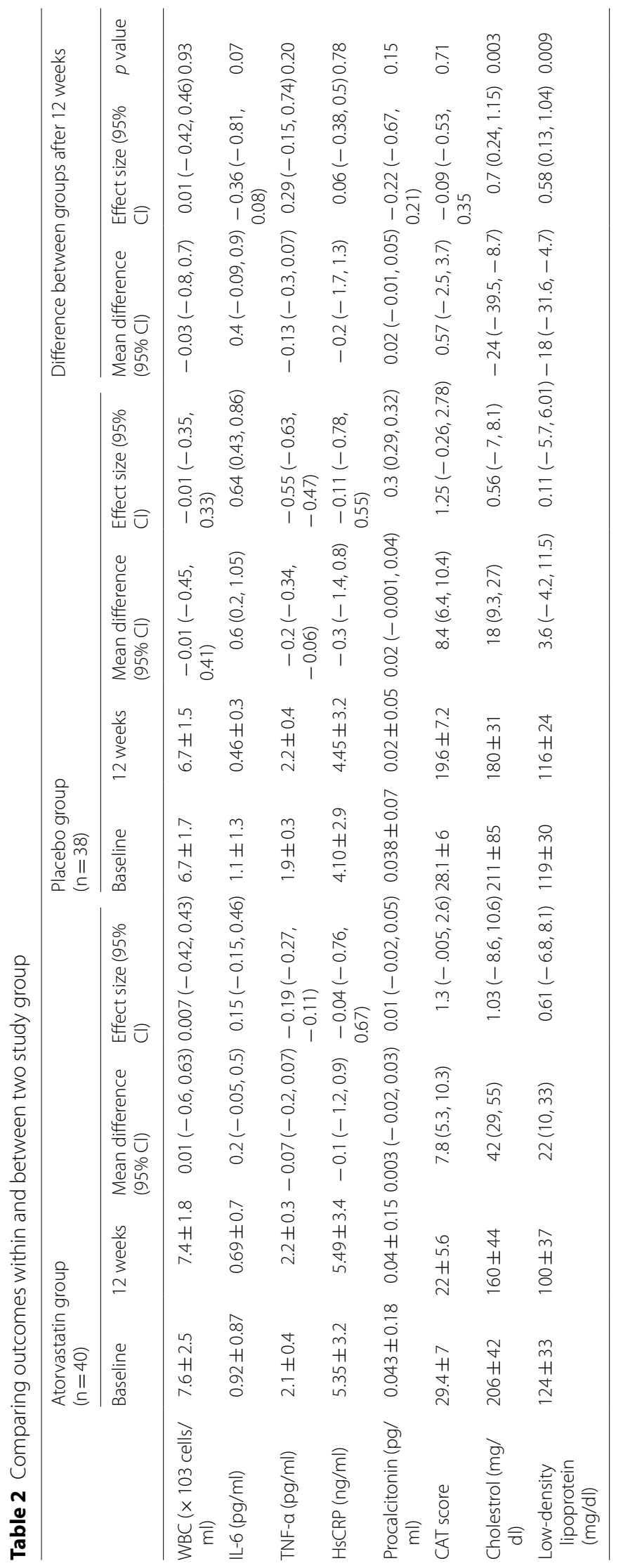


between groups. The lipid lowering effect of statins is independent of CRP lowering effect [26]. The benefit of intensive statin therapy is likely due to reduced level of both LDL and CRP. In contrary to Devaraj et al. [26] that had hypothesized the early benefit of statins might have been related to reduction of CRP presented preceding to their lipid lowering effect, our results showed lipid lowering effect without statistically significant reduction in HsCRP. The optimal level of statin to obtain the antiinflammatory goals remains to be established; the antiinflammatory effect of atorvastatin might require higher dose or longer duration. As it was stated in the method section, we included patients with stable mustard gas induced bronchitis, which might explain why the level of inflammatory markers was not statistically significant between the groups. On the other hand, the main site of inflammation in bronchitis is the lungs, and to be more precise, as Kaczmarek et al. [28] had suggested, it might be better to assess the inflammatory markers in bronchoalveolar washing.

We had initially thought that the power of our study was sufficient and acceptable to detect relatively moderate differences between atorvastatin and placebo groups; however, due to wider standard deviation than expected, it is likely that this study was slightly underpowered on post-hoc power analysis by $\mathrm{G}$ power [30].

The CAT score is a disease-specific instrument for assessing the severity of COPD [22, 31, 32]. Although the CAT score of our participants met the minimum of clinical important differences [33] of a 2-unit reduction in both groups, its mean differences was not significant between groups (mean difference [95\% CI]: $0.57[-2.5$, 3.7]). The CAT score reduction in the placebo group can be explained by placebo effect [34]. In contrary to our findings, Maneechotesuwan et al. [35] studied the effect of simvastatin $20 \mathrm{mg}$ daily versus placebo on sputum inflammatory markers, airway inflammation, and CAT score of 30 patients with stable COPD, and found clinically significant important reduction in CAT score after statin administration. Mandal and colleagues, in a clinical trial assessing the role of atorvastatin in treating bronchiectasis, reported that the patients who received statins had a better quality of life (the St George's Respiratory Questionnaire) in comparison to those who had received placebo, nevertheless they did not reach minimum clinically important difference of a 4-unit reduction in SGRQ score [36].

\section{Limitations}

This study had two limiting factors that debilitated the results. First, the participants were in relatively stable state of their disease, which might have reduced the effectiveness of statin. Second, we merely focused on few systemic inflammatory markers in a limited period of time, while the main source of inflammation in patients with bronchitis is the lung.

Therefore, larger prospective randomized controlled trials with longer follow up that focus on the respiratory tract indices, like exhaled air condensate or bronchoalveolar lavage, both during stable periods and exacerbations [28] and/or other systemic inflammatory, such as monocyte-macrophage function [26] is warranted.

\section{Conclusion}

Despite its limitations, this study provides evidence that administration of $40 \mathrm{mg}$ atorvastatin for 3 months cannot significantly reduce systemic inflammatory factors in the patients with chronic bronchitis due to sulfur mustard gas inhalation.

\section{Abbreviations}

BMI: Body mass index; CAT: COPD assessment test score; CRP: C reactive protein; COPD: Chronic obstructive pulmonary disease; Hb: Hemoglobin; IL-6: Interleukin 6; LFTs: Liver-function tests; PCT: Procalcitonin; TG: Triglyceride; TNFa: Tumor necrosis factor a.

\section{Supplementary Information}

The online version contains supplementary material available at https://doi. org/10.1186/s12890-021-01481-y.

Additional file 1. The raw data of this study.

\section{Acknowledgements}

This article was extracted from the theses written by Behrouz Momeni (for the degree of subspecialty in pulmonary) and Saeed Nazer (for the degree of specialty in medicine). The authors wish to thank Mr. H. Argasi at HR Publication for his invaluable assistance in editing this manuscript.

\section{Authors' contributions}

BM, SN and SVS contributed in the participants' enrollment and followed them to the end of study and co-wrote the draft. SMM and BG contributed to the study design, analyzed and interpreted the patient data, and critically appraised the manuscript. All authors read and approved the final manuscript.

\section{Authors' information}

Behrooz Momeni: Fellowship of pulmonary subspecialty, Shiraz University of medical Sciences, Shiraz, Iran.

Saeed Nazer: Resident of internal medicine, Student Research committee, Shiraz University of medical Sciences, Shiraz, Iran.

Seyed Masoom Masoompour: Professor of medicine, Shiraz University of medical Sciences, Shiraz, Iran.

Bita Geramizadeh: Professor of pathology, Shiraz University of medical Sciences, Shiraz, Iran.

Seyed Vahid Sajjadi: Resident of emergency medicine, Shiraz University of medical Sciences, Shiraz, Iran.

\section{Funding}

Vice-chancellor of Research at Shiraz University of Medical Sciences, Iran (grant No. 7108 and 7574), did not have any role in the design, analysis, interpretation of data or in writing the manuscript. 


\section{Availability of data and materials}

All data generated during this study are included in this manuscript (Additional file 1).

\section{Declarations}

\section{Ethics approval and consent to participate}

All procedures performed in studies involving human participants were in accordance with the ethical standards of the Institutional Research Ethics Committee of Shiraz University of Medical Sciences and with the 1964 Helsinki declaration and its later amendments or comparable ethical standards. Written informed consent was obtained from all participants in this study.

\section{Consent to publication}

Not applicable.

\section{Competing interests}

The authors declare that they have no conflict of interest.

\begin{abstract}
Author details
${ }^{1}$ Department of Internal Medicine, School of Medicine, Shiraz University of Medical Sciences, Shiraz 7193634154, Iran. ${ }^{2}$ Student Research Committee, Shiraz University of Medical Sciences, Shiraz, Iran. ${ }^{3}$ Non-Communicable Diseases Research Center, Department of Internal Medicine, School of Medicine, Shiraz University of Medical Sciences, Shiraz, Iran. ${ }^{4}$ Transplant Research Center, Department of Pathology, School of Medicine, Shiraz University of Medical Sciences, Shiraz, Iran. ${ }^{5}$ Department of Emergency Medicine, School of Medicine, Shiraz University of Medical Sciences, Shiraz, Iran.
\end{abstract}

Received: 4 June 2020 Accepted: 25 March 2021

Published online: 01 April 2021

\section{References}

1. Nations SCotU. Report of specialists appointed by the Secretary General to investigate allegations by the Islamic Republic of Iran concerning the use of chemical weapons. Security Council of the United Nations, document S/16433, New York; 1986.

2. Willems J. Clinical management of mustard gas casualties. Ann Med Mil Belg. 1989;3(Suppl 1):1-61.

3. Ray R, Hauck S, Kramer R, Benton B. A convenient fluorometric method to study sulfur mustard-induced apoptosis in human epidermal keratinocytes monolayer microplate culture. Drug Chem Toxicol. 2005;28(1):105-16.

4. Taghaddosinejad F, Fayyaz AF, Behnoush B. Pulmonary complications of mustard gas exposure: a study on cadavers. Acta Med Iran. 2011:49(4):233.

5. Sohrabpour H, Masjedi M, Bahadori M. Late complications of sulfur mustard in respiratory system. Med J Islamic Repub Iran. 1988;2(3):171-4.

6. Emad A, Rezaian GR. The diversity of the effects of sulfur mustard gas inhalation on respiratory system 10 years after a single, heavy exposure: analysis of 197 cases. Chest. 1997;112(3):734-8.

7. Hoseini K, Alavi S, Abedi A. Reversibility of airflow obstruction in chronic obstructive disease secondary to sulfur mustard gas injury. Arch Iran Med. 1999:2:178-80.

8. Kumar O, Sugendran K, Vijayaraghavan R. Protective effect of various antioxidants on the toxicity of sulphur mustard administered to mice by inhalation or percutaneous routes. Chem Biol Interact. 2001;134(1):1-12

9. Anderson DR, Byers SL, Vesely KR. Treatment of sulfur mustard (HD)induced lung injury. J Appl Toxicol. 2000;20(S1):S129-32.

10. Anderson DR, Holmes WW, Lee RB, Dalal SJ, Hurst CG, Maliner BI, et al. Sulfur mustard-induced neutropenia: treatment with granulocyte colony-stimulating factor. DTIC Document; 2006.

11. Anderson DR, Taylor SL, Fetterer DP, Holmes WW. Evaluation of protease inhibitors and an antioxidant for treatment of sulfur mustard-induced toxic lung injury. Toxicology. 2009;263(1):41-6.
12. Allon N, Amir A, Manisterski E, Rabinovitz I, Dachir S, Kadar T. Inhalation exposure to sulfur mustard in the guinea pig model: clinical, biochemical and histopathological characterization of respiratory injuries. Toxicol Appl Pharmacol. 2009;241(2):154-62.

13. Fairhall S, Brown R, Jugg B, Smith A, Mann T, Jenner J, et al. Preliminary studies of sulphur mustard-induced lung injury in the terminally anesthetized pig: exposure system and methodology. Toxicol Mech Methods. 2008;18(4):355-62.

14. Beheshti J, Mark EJ, Akbaei HMH, Aslani J, Ghanei M. Mustard lung secrets: long term clinicopathological study following mustard gas exposure. Pathology-Research and Practice. 2006;202(10):739-44.

15. Rowell M, Kehe K, Balszuweit F, Thiermann $H$. The chronic effects of sulfur mustard exposure. Toxicology. 2009;263(1):9-11.

16. Malaviya R, Sunil VR, Cervelli J, Anderson DR, Holmes WW, Conti ML, et al. Inflammatory effects of inhaled sulfur mustard in rat lung. Toxicol Appl Pharmacol. 2010;248(2):89-99.

17. Kwak B, Mulhaupt F, Myit S, Mach F. Statins as a newly recognized type of immunomodulator. Nat Med. 2000;6(12):1399-402.

18. Mohammad S, Nguyen $H$, Nguyen M, Abdel-Rasoul M, Nguyen $V$, Nguyen CD, et al. Pleiotropic effects of statins: untapped potential for statin pharmacotherapy. Curr Vasc Pharmacol. 2019;17(3):239-61.

19. Sapey E, Patel JM, Greenwood H, Walton GM, Grudzinska F, Parekh D, et al. Simvastatin improves neutrophil function and clinical outcomes in pneumonia. A pilot randomized controlled clinical trial. Am J Respir Crit Care Med. 2019;200(10):1282-93.

20. Watts KL, Sampson EM, Schultz GS, Spiteri MA. Simvastatin inhibits growth factor expression and modulates profibrogenic markers in lung fibroblasts. Am J Respir Cell Mol Biol. 2005;32(4):290-300.

21. Sathyapalan T, Atkin SL, Kilpatrick ES. Disparate effects of atorvastatin compared with simvastatin on C-reactive protein concentrations in patients with type 2 diabetes. Diabetes Care. 2010;33(9):1948-50.

22. Jones P, Harding G, Berry P, Wiklund I, Chen W, Leidy NK. Development and first validation of the COPD Assessment Test. Eur Respir J. 2009;34(3):648-54

23. DeFife J. Effect size calculator: Emory University; 2009. https://calcu lator.web.cs.dal.ca.

24. Lenhard WL, A. Calculation of effect sizes 2016. cited 2020. https:// www.psychometrica.de/effect_size.html.

25. Stigler SM. Regression towards the mean, historically considered. Stat Methods Med Res. 1997;6(2):103-14.

26. Devaraj S, Rogers J, Jialal I. Statins and biomarkers of inflammation. Curr Atheroscler Rep. 2007:9(1):33-41.

27. Walsh A, Perrem L, Khashan AS, Henry MT, Ni CM. Statins versus placebo for people with chronic obstructive pulmonary disease. Cochrane Database Syst Rev. 2019;7(7):Cd011959.

28. Kaczmarek P, Sladek K, Skucha W, Rzeszutko M, Iwaniec T, Dziedzina S, et al. The influence of simvastatin on selected inflammatory markers in patients with chronic obstructive pulmonary disease. Pol Arch Med Wewn. 2010;120(1-2):11-7.

29. Emad A, Koushki A. The impact of concurrency of colchicine and simvastatin on variation of serum immunoglobulins $\lg G, \lg E$, IgM and IgA in mustard gas-wounded patients. Biosci Biotechnol Res Asia. 2016;13(1):59-65.

30. Faul F, Erdfelder E, Lang A-G, Buchner A. G*Power 3: A flexible statistical power analysis program for the social, behavioral, and biomedical sciences. Behav Res Methods. 2007;39(2):175-91.

31. Ghobadi H, Ahari SS, Kameli A, Lari SM. The relationship between COPD Assessment Test (CAT) scores and severity of airflow obstruction in stable COPD patients. Tanaffos. 2012;11(2):22-6.

32. Jones PW, Brusselle G, Dal Negro RW, Ferrer M, Kardos P, Levy ML, et al. Properties of the COPD assessment test in a cross-sectional European study. Eur Respir J. 2011;38(1):29-35.

33. Kon SS, Canavan JL, Jones SE, Nolan CM, Clark AL, Dickson MJ, et al. Minimum clinically important difference for the COPD Assessment Test: a prospective analysis. Lancet Respir Med. 2014;2(3):195-203.

34. Vollert J, Cook NR, Kaptchuk TJ, Sehra ST, Tobias DK, Hall KT. Assessment of placebo response in objective and subjective outcome measures in rheumatoid arthritis clinical trials. JAMA Netw Open. 2020;3(9):e2013196-e. 
35. Maneechotesuwan K, Wongkajornsilp A, Adcock IM, Barnes PJ. Simvastatin suppresses airway IL-17 and upregulates IL-10 in patients with stable COPD. Chest. 2015;148(5):1164-76.

36. Mandal P, Chalmers JD, Graham C, Harley C, Sidhu MK, Doherty C, et al. Atorvastatin as a stable treatment in bronchiectasis: a randomised controlled trial. Lancet Respir Med. 2014;2(6):455-63.

\section{Publisher's Note}

Springer Nature remains neutral with regard to jurisdictional claims in published maps and institutional affiliations.
Ready to submit your research? Choose BMC and benefit from:

- fast, convenient online submission

- thorough peer review by experienced researchers in your field

- rapid publication on acceptance

- support for research data, including large and complex data types

- gold Open Access which fosters wider collaboration and increased citations

- maximum visibility for your research: over $100 \mathrm{M}$ website views per year

At BMC, research is always in progress.

Learn more biomedcentral.com/submissions 